\title{
The Efficiency of Sequestering Carbon in Agricultural Soils
}

Gregory R. Pautsch, Lyubov A. Kurkalova, Bruce A. Babcock, and Catherine L. Kling

Working Paper 00-WP 246

August 2000 


\title{
The Efficiency of Sequestering Carbon in Agricultural Soils
}

\author{
Gregory R. Pautsch, Lyubov A. Kurkalova, \\ Bruce A. Babcock, and Catherine L. Kling
}

Working Paper 00-WP 246

August 2000

\author{
Center for Agricultural and Rural Development \\ lowa State University \\ Ames, lowa 50011-1070 \\ www.card.iastate.edu
}

Gregory R. Pautsch was an associate scientist with the Center for Agricultural and Rural Development (CARD) when this paper was written. Lyubov A. Kurkalova is a post-doctoral research associate; Bruce A. Babcock is director of CARD and professor of economics; and Catherine L. Kling is head of the Resource and Environmental Policy Division and professor of economics, Center for Agricultural and Rural Development, lowa State University.

This is Journal Paper No. J-18435 of the lowa Agriculture and Home Economics Experiment Station, Ames, lowa; Project No. 3363, supported by Hatch Act and State of lowa funds. We thank three referees whose comments significantly improved the modeling framework and exposition. Thanks also go to Todd Campbell for incredible programming assistance and Jinhua Zhao for helpful suggestions.

This publication is available online on the CARD website www.card.iastate.edu. Permission is granted to reproduce this information with appropriate attribution to the authors and the Center for Agricultural and Rural Development, lowa State University, Ames, lowa 50011-1070.

For questions or comments about the contents of this paper, please contact Catherine L. Kling, 568D Heady Hall, lowa State University, Ames, IA 50011-1070, Ph: 515-294-5767, Fax: 515-294-6336, email: ckling@iastate.edu.

lowa State University does not discriminate on the basis of race, color, age, religion, national origin, sexual orientation, sex, marital status, disability, or status as a U.S. Vietnam Era Veteran. Any persons having inquiries concerning this may contact the Director of Affirmative Action, 318 Beardshear Hall, 515-294-7612. 


\begin{abstract}
Agricultural tillage practices are important human-induced activities that can alter carbon emissions from agricultural soils and have the potential to significantly contribute to reductions in greenhouse gas emission (Lal et al, 1998). This research investigates the expected costs of sequestering carbon in agricultural soils under different subsidy and market-based policies. Using the detailed National Resources Inventory data, we estimate the probability that farmers adopt conservation tillage practices based on a variety of exogenous characteristics and profit from conventional practices. These estimates are used with physical models of carbon sequestration to estimate the subsidy costs of achieving increased carbon sequestration with alternative subsidy schemes.
\end{abstract}

JEL classification code: Q38 Nonrenewable Resources and Conservation - Government Policy. 


\section{Introduction}

The Kyoto Protocol to the United Nations Framework Convention on Climatic Change (UNFCCC, 1998) proposes to limit future aggregate anthropogenic carbon dioxide equivalent greenhouse gas emissions (Article 3.1). The Kyoto Protocol also establishes the concept of credits for carbon sinks. These credits can be used to meet a country's emission limitation and reduction commitment. Currently, carbon sinks are limited to recent efforts in afforestation, reforestation, and deforestation and do not include agricultural soils (Article 3.3). However, Article 3.4 leaves the future inclusion of agricultural soils a distinct possibility by stating “...Parties to this Protocol shall...decide upon modalities, rules, and guidelines as to how, and which, additional human-induced activities related to greenhouse gas emissions by sources and removals by sinks in the agricultural soils and the land use change and forestry categories shall be added to or subtracted from the assigned amounts..."

Conservation tillage is the primary means of increasing soil carbon. Conservation tillage uses crop residue to serve as mulch to protect and increase the soil organic carbon (SOC) levels. Conventional tillage systems disturb the soil, leading to oxidation and subsequent loss of soil carbon, and leave it unprotected from wind and rainfall, resulting in a decrease in SOC levels. Increasing the adoption of conservation tillage will increase carbon sequestration rates in agricultural soils and decrease the greenhouse gas emissions from the agricultural sector (Lal et al, 1998).

The purpose of this research is to examine various government and market-based instruments to reduce the amount of carbon emissions from agricultural soils through the increased adoption of conservation tillage. First, the farmer's adoption decision is formally modeled. Next, the design of subsidy and market based instruments are discussed with specific focus on the institutions and practices surrounding agricultural 
policy. Finally, the costs of implementing a variety of subsidy and market based schemes are estimated and compared.

\section{A Model of Conservation Tillage Adoption and Carbon Sequestration}

In this section, we present a simple adoption model of the farmer's tillage choice and a model of changes in carbon soil levels. Carbon sequestration levels will depend on the farmer's choice of tillage practice and the environmental impact of that choice. Hence, the expected change in environmental quality from a newly instituted policy depends on the increased probability that conservation tillage is adopted and the expected change in soil carbon levels. Since both adoption probabilities and the change in carbon levels vary across production sites, the site-specific expected change in environmental quality must be aggregated across all sites to obtain the aggregate change in expected supply.

Producers will adopt either a conventional or conservation tillage system when growing their crops. Conservation tillage generally lowers fuel, labor, and machinery costs more than conventional tillage. Unfortunately, it may also adversely affect yields, resulting in lower profits for some farmers. In the absence of subsidies, some farmers will find it desirable to adopt conservation tillage practices while others will not. Producers are assumed to be risk neutral and hence will adopt the tillage system that maximizes expected returns. A rationale for this assumption is that the change in the magnitude of risk that occurs from choice of tillage practice relative to the amount of production and price risk is quite low.

Let a superscript " 1 " denote conservation tillage, and a superscript " 0 " denote conventional tillage. Let $E \pi^{1}$ denote the expected returns from conservation tillage and $\bar{\pi}^{0}$ be the known, average returns from conventional tillage. Thus, a conservation tillage system is adopted when the expected returns from conservation tillage exceed the expected returns from conventional tillage, i.e., $E \pi^{1}>\bar{\pi}^{0}$.

Since conservation tillage represents a relatively new practice for many farmers, the returns from conservation tillage are not always well understood. Thus, we adopt the standard assumption that these returns, while known to individual farmers, are not 
observable to the researcher. However, the expected returns from conventional tillage and the choice of tillage system are observable as well as production and geographical characteristics such as weather, land, and cropping patterns.

The expected returns to a farmer from a conservation tillage system are modeled as linearly related to the vector of observable production characteristics (x),

$$
E \pi^{1}=\beta x+\sigma \varepsilon,
$$

where greek letters represent coefficients and eis an additive random error. Let $Y=1$ denote the adoption of conservation tillage and $Y=0$ denote the use of conventional tillage. The probability of adopting conservation tillage given production characteristics $\mathrm{x}$ is,

$$
\begin{aligned}
\operatorname{Pr} & {\left[Y=1 \mid x, \bar{\pi}^{0}\right]=\operatorname{Pr}\left[E \pi^{1}>\bar{\pi}^{0} \mid x, \bar{\pi}^{0}\right] } \\
& =\operatorname{Pr}\left[\varepsilon>\frac{\bar{\pi}^{0}-\beta x}{\sigma} \mid x, \bar{\pi}^{0}\right]=1-\operatorname{Pr}\left[\varepsilon \leq \frac{\bar{\pi}^{0}-\beta x}{\sigma} \mid x, \bar{\pi}^{0}\right] .
\end{aligned}
$$

The error term, $\varepsilon$, is assumed to be logistically distributed. The logistic distribution is chosen both for its ease of estimation and its well-known similarity to results from a normal distribution (Amemiya, 1981; Maddalla, 1983). So then,

$$
\begin{aligned}
& \operatorname{Pr}\left[Y=1 \mid x, \bar{\pi}^{0}\right]=\frac{\exp \left(\alpha \bar{\pi}^{0}+\tilde{\beta} x\right)}{1+\exp \left(\alpha \bar{\pi}^{0}+\tilde{\beta} x\right)} \equiv G\left(\alpha \bar{\pi}^{0}+\tilde{\beta} x\right), \\
& \text { where, } \alpha=-\frac{1}{\sigma} \text { and } \tilde{\beta}=\frac{\beta}{\sigma} .
\end{aligned}
$$

The product of these probabilities over the sample forms the likelihood function for estimation. Note that the inclusion of expected returns to conventional tillage, as suggested by the theoretical model, uniquely identifies the value of the coefficients in the logistic estimation.

Now suppose a payment $\mathrm{k}$ is offered to further entice the adoption of conservation tillage practices. The adoption will occur if the expected returns from conservation tillage plus the payment exceed the expected returns from conventional tillage, i.e., $E \pi^{1}+k>\bar{\pi}^{0}$. With payments, the probability of adopting conservation tillage practices with production characteristics $\mathrm{x}$ becomes, 


$$
\begin{gathered}
\operatorname{Pr}\left[Y=1 \mid x, \bar{\pi}^{0}\right]=1-\operatorname{Pr}\left[\varepsilon \leq \frac{\bar{\pi}^{0}-\beta x-k}{\sigma} \mid x, \bar{\pi}^{0}\right] \\
=\frac{\exp \left(\alpha\left(\bar{\pi}^{0}-k\right)+\tilde{\beta} x\right)}{1+\exp \left(\alpha\left(\bar{\pi}^{0}-k\right)+\tilde{\beta} x\right)}=G\left(\alpha\left(\bar{\pi}^{0}-k\right)+\tilde{\beta} x\right) .
\end{gathered}
$$

The magnitude of carbon emissions from different tillage practices depends upon various production and geographical characteristics such as soil, weather, land, and cropping history. Suppose there are $I$ different production sites indexed by the subscript $i$, $i=1, \ldots, I$. Denote the per acre carbon emissions from the $i^{\text {th }}$ production site when using conventional and conservation tillage as $Y 0\left(x_{i}\right)$ and $Y 1\left(x_{i}\right)$. With payments, the total expected amount of carbon sequestered from the $i^{\text {th }}$ production site, $Q_{i}\left(k \mid x_{i}, \bar{\pi}_{i}^{0}\right)$, is simply the difference between the amount of carbon released into the atmosphere if conventional tillage is used minus the expected amount of carbon emitted into the atmosphere under the payment,

$$
Q_{i}\left(k \mid x_{i}, \bar{\pi}_{i}^{0}\right)=G\left(\alpha\left(\bar{\pi}_{i}^{0}-k\right)+\tilde{\beta} x_{i}\right)\left[Y 0\left(x_{i}\right)-Y 1\left(x_{i}\right)\right] N A_{i},
$$

where $\mathrm{NA}_{\mathrm{i}}$ is the number of acres at the site.

\section{The Design of Carbon Sequestration Policy for Agriculture}

From the last section, it is clear that different subsidies or payments to farmers will generate different carbon sequestration rates. In this section, we present and discuss alternative policies that the U.S. government might adopt in response to an agreement by the international community to include agricultural sequestration in accounting for greenhouse gas reductions.

Regardless of the policy adopted, the baseline level of soil carbon levels after which increases will be counted towards emission reductions will be a critical issue in the role that agriculture will play in greenhouse gas reduction efforts. This issue will be resolved by international negotiation, although the degree to which the United States is a "large player" in that venue may affect the outcome. We suppose that there are two possibilities. First, only increments to carbon sequestration levels above the levels observed just before the time of adoption of the international agreement will be counted. Thus, credit for 
carbon emission reductions will be available to agriculture only for carbon reductions achieved through new adopters of conservation tillage. The second alternative is that credit is given for all carbon sequestered in the soil. Thus, credit for carbon emission reductions will be available to all adopters-new or previous adopters. Although at first sight, the former approach may seem more appropriate, there is the very real possibility that if previous adopters are not credited and able to receive subsidies or payments, they will simply plow up their land to become eligible as "new adopters." Antle et al. (2000) and Sandor and Skees (1999) raise this concern.

The possible alternative designs of a government-based subsidy program to encourage the adoption of conservation tillage might be offered under the auspices of the current Environmental Quality Incentives Program (EQIP). EQIP offers financial, educational, and technical assistance where significant natural resource problems, such as soil erosion, exist. Two general possibilities exist for the form of the subsidy:

- a single per acre subsidy, where each producer is offered the same amount of subsidy per acre to adopt conservation tillage practices, or

- a price discriminating or targeted subsidy, where different per acre payments are offered to farmers based on their ability to sequester carbon.

Throughout the remainder of the paper we refer to the first form of subsidy as the "single" per acre subsidy and the second as the price discriminating subsidy. In its extreme form, and the form we study here, the discriminating subsidy achieves the lowest payment cost of sequestering an expected level of carbon. If there are important differences in land characteristics and adoption potential across locations and farmers, these two subsidies could be associated with vastly different administrative costs and payments for acquiring carbon. Although likely infeasible in its purest form (due to the need to offer different subsidies to farmers based on their carbon sequestering capability) a perfectly discriminating subsidy is of interest since it provides a lower bound on the costs of sequestering carbon from agricultural practices (exclusive of the administrative costs).

Other possible EQIP subsidy programs could vary the subsidy payment according to the producer's location and/or crop grown, thus achieving some of the cost saving from 
differentiation, but at more reasonable administrative costs than the least cost subsidy. By focussing on the two endpoints - no differentiation and complete differentiation - this analysis provides the range of subsidy payment costs from the most easily administered (single subsidy payment) to the most difficult (least cost).

Formally, a subsidy program is a collection of subsidies, denoted by $k=\left(k_{m n}\right)$, where $k_{m n}$ is the per acre subsidy offered to the producer at the $n^{\text {th }}$ site growing the $m^{\text {th }}$ crop. The expected number of acres using conservation tillage practices under an EQIP subsidy program $k$ is denoted as $N A(k)$ and equal to,

$$
N A(k)=\sum_{m=1}^{M} \sum_{n=1}^{r_{m}} G\left(\alpha\left(\bar{\pi}_{m n}^{0}-k_{m n}\right)+\tilde{\beta} x_{m n}\right) N A_{m n}
$$

where $x_{m n}$ represents the production characteristics of the $n^{\text {th }}$ site growing the $m^{\text {th }}$ crop, $\bar{\pi}_{m n}^{0}$ is the average return from conventional tillage on the $n^{\text {th }}$ site growing the $m^{\text {th }}$ crop, $M$ is the number of crops, and $r_{m}$ is the number of production sites growing the $m^{\text {th }}$ crop.

The total expected level of carbon sequestration, $Q(k)$, is equal to the sum of the expected amount of carbon sequestered by each producer,

$$
Q(k)=\sum_{m=1}^{M} \sum_{n=1}^{r_{m}} Q_{m n}\left(k_{m n} \mid x_{m n}, \bar{\pi}_{m n}^{0}\right)
$$

where $Q_{m n}$ is the expected supply of carbon from the $n^{\text {th }}$ site growing the $m^{\text {th }}$ crop.

In the case of a single subsidy scheme, $k_{m n}=\bar{k}$, for all $(m, n)$, each per acre payment level will yield a different total amount of carbon sequestered (8). Thus, the authority can choose the single per acre subsidy value to achieve the desired expected supply of carbon.

In contrast, the discriminating subsidy scheme will be comprised of a set of differing payments that minimize the total expected cost of acquiring a given level of expected carbon, $\bar{Q}$. The payment minimizing set of subsidies is found by solving,

$$
\underset{k_{m n}}{\operatorname{Min}} L=\sum_{m=1}^{M} \sum_{n=1}^{r_{m}} k_{m n} G\left(\alpha\left(\bar{\pi}_{m n}^{0}-k_{m n}\right)+\tilde{\beta} x_{m n}\right) N A_{m n}+\lambda\left[\bar{Q}-\sum_{m=1}^{M} \sum_{n=1}^{r_{m}} Q_{m n}\left(k_{m n} \mid x_{m n}, \bar{\pi}_{m n}^{0}\right)\right] .
$$


The first order condition states that at the minimum ${ }^{1}$ the expected marginal cost of acquiring carbon is equal across all producers and can be written

$$
\begin{aligned}
& \lambda^{*}=\left[\frac{k_{m n}^{*}}{Y 0\left(x_{m n}\right)-Y 1\left(x_{m n}\right)}\right]\left[1+\frac{1}{\omega_{m n}}\right] \text { for } m=1, \ldots, M ; i=1, \ldots, r_{m} \\
& \text { where } \omega_{m n}=\left[\frac{\partial G(\cdot)}{\partial k_{m n}}\right]\left[\frac{k_{m n}}{G(\cdot)}\right]=\text { elasticity of adoption. }
\end{aligned}
$$

The variable $\lambda^{*}$ represents the optimal expected marginal cost of acquiring carbon, and $k_{m n}^{*}$ represents its optimal subsidy. As indicated, the optimal subsidy offered to producers depends upon their willingness to adopt conservation tillage practices and their ability to sequester carbon through conservation tillage practices. The elasticity of adoption $\left(\omega_{m n}\right)$ represents a producer's willingness to adopt conservation practices. The greater the elasticity of adoption, the greater the increase in the probability of adopting conservation tillage for a marginal increase in the subsidy. Per acre differences in the amount of carbon emissions between conventional and conservation tillage $\left(Y 0\left(x_{m n}\right)-Y 1\left(x_{m n}\right)\right)$ represents the producer's ability to sequester carbon.

The need to provide a different subsidy for each farmer may initially appear at odds with the standard environmental economics result that efficient allocations are achieved with a constant payment per unit of emissions. However, the subsidy scheme discussed here is not based directly on emissions, but rather on an acre basis. To the extent that different acres have different emission reduction potential, different levels of subsidies are necessary to achieve efficiency.

In addition to choosing between a single subsidy and a discriminating subsidy, the government must decide whether existing adopters will be eligible for subsidies or whether only new adopters will be eligible. Although a subsidy scheme that only pays new adopters will clearly be much cheaper, it is unclear whether such a subsidy scheme is viable. First there is the question of fairness - strong arguments are likely to be made that farmers who adopted environmentally beneficial practices early should not be penalized for doing so. Second, there is an important efficiency concern. If the subsidy scheme is developed such that only new adopters are eligible, all farmers have an incentive to 
become a "new" adopter. This can be achieved by existing adopters by converting to conventional tillage practices for a year, thereby releasing most of their stored carbon reserves into the atmosphere. Clearly this is not an efficient outcome and it could be avoided by paying all adopters.

The preceding discussion has been framed in terms of subsidy schemes; however, many of the issues discussed would be directly relevant to a carbon permit market. In such a market, producers might receive carbon credits from the government, redeemable in an organized carbon market outside of the agricultural sector. Given the market price of carbon, producers could either sell their carbon credits and use conservation tillage practices or keep their carbon credits and use conventional practices. For such a market to work in agriculture, there must, of course, be a well functioning carbon market in sectors outside of agriculture.

Again, the setting of the baseline against which improvements are measured will be an important determinant in the potential magnitude of this market. If the baseline is set such that only newly sequestered carbon can count toward the international agreement limits, then it would make sense to design the market such that farmers are given credits only to cover new adoption. Thus, farmers already having adopted conservation tillage practices would not receive any credits. In contrast, if the baseline is set at zero, farmers would receive carbon credits equal to the total carbon potential of their land, regardless of whether they had previously adopted or not.

Likewise, the issue of spatial heterogeneity is equally relevant. A credit program could conceptually be set up such that each farmer received credits equal to the specific carbon potential of their land, accounting for soil characteristics, historical cropping patterns, weather, etc. This would correspond to our price discriminating subsidy scheme. Alternatively, each acre could be given a fixed amount of credit, regardless of its characteristics. This would correspond to the single subsidy scheme.

\section{Estimation of the Tillage Adoption Model}

The study region consists of the state of Iowa, where there is good data on tillage practices, returns to conventional tillage, and land characteristics. Further, Iowa soil has 
been identified as soil with very high potential for carbon sequestration (Mitchell, 1997). The crops in the analysis are corn, soybeans, wheat, sorghum, and hay and fourteen major rotations were identified (Babcock et al., 1997). The primary data source is the U.S. Department of Agriculture (USDA) National Resource Conservation Service's National Resource Inventory (NRI) conducted at 13,477 points in the study area. For each NRI point, information is collected on the natural resource characteristics of the land, the farming practices used by the producer, and weather characteristics. The NRI data are supplemented by constructed net returns and climate data.

Two samples were used in the empirical analysis: the whole sample for the study region, and a random sub-sample. First, the logit model of conservation tillage adoption was estimated on a random sub-sample (1,343 points) drawn from NRI points located in the study region. Second, the probabilities of conservation tillage adoption under different subsidy schemes and the expected levels of carbon sequestration were predicted on the whole NRI sample for the study region $(13,477$ points).

Table 1 presents the variables used in the estimation of the conservation tillage adoption model. All data are for the 1992-growing season. As can be seen from the table, 62 percent of farmers already use conservation tillage. These farmers have chosen to adopt conservation tillage in the absence of subsidies, presumably because the net benefit of conservation tillage on their farms is positive (the lower expected yields are more than offset by lower costs of production).

The expected net returns from conventional tillage, $E \pi^{1}$, are distinguished by crop in Table 1 and are those realized in 1992. Since returns data are not available from the NRI data, we assigned the net returns data to each sample point based on the production region, 1992 crop, and 1991 crop information. To construct the regional returns data, we combined county-specific average yield data (USDA/NASS, 1994), state-specific price data (USDA/NASS, 1999), and the region-, tillage-, and rotation-specific cost data from Mitchell (1997). The sample average net returns to conventional tillage in corn production is about $\$ 145 /$ acre, in soybeans about $\$ 110$ acre and about $\$ 92 /$ acre for all other crops. A dummy variable indicating a crop other than corn or soybeans ("other 
crops") is included to account for the somewhat idiosyncratic nature of these other choices (over 90 percent of Iowa is planted in corn or soybeans).

Climatic data were constructed for the usual crop growing seasons as reported in USDA/NASS (1997), from 1975-1994 temperature and precipitation data collected by the National Climatic Data Center (Earthinfo, 1995). The remaining variables used are indicators of land characteristics that have been identified as either favorable to or difficult for conservation tillage practices. The impact of natural soil and climate conditions on conservation tillage adoption depends on two factors: (a) whether there is an identified need for conservation efforts to sustain agricultural production, and/or (b) whether conservation tillage can provide physical soil condition benefits as compared to conventional tillage. The first factor refers to adoption of conservation tillage to prevent losses associated with a long-term use of conventional tillage, while the second factor refers to gains associated with the conservation tillage adoption.

Regarding the first factor, one would expect a wider adoption of conservation tillage on the lands prone to wind and water erosion. As for the second factor, field experiments show that an increase in the amount of crop residue cover on the soil surface tends to keep soils cooler, wetter, less aerated, and denser (eg., Allmaras and Dowdy, 1985; Uri, 1999). Consequently, wider adoption of conservation tillage is expected on the soils where these effects are desirable.

Table 2 presents the estimated influence of each of these variables on the probability of adopting conservation tillage as well as the standard error. The estimated net returns coefficients suggest that the standard deviation of the returns to conservation tillage is about $\$ 150$ for corn and $\$ 130$ for soybeans. While high compared to the conventional tillage returns reported in Table 1, it is important to keep in mind that the true variability of the returns to conventional tillage is higher as the returns were averaged over individual farmers in constructing the data.

Estimates of the effect of soil and climatic conditions on conservation tillage adoption are reasonable. Land slope is the amount of inclination of the soil surface from the horizontal expressed as the vertical distance divided by the horizontal distance. The slope is one of the key factors affecting land susceptibility to soil erosion, which in turn, 
should affect adoption of conservation techniques. As expected, we found a statistically significant positive relationship between this variable and the probability of adoption, a result consistent with earlier studies of Wu and Babcock (1998) and Uri (1998).

Soil permeability (the rate at which water can pass through a soil material) and available water capacity (the amount of water that a soil can store in a form available for plant use) are both positively related to better drainage of the soil, which in turn, is found to positively affect yields under conservation tillage systems (see, for example, a discussion in Allmaras and Dowdy, 1985). Thus, the found strong positive effects of these variables on conservation tillage adoption are in agreement with agronomic and soil science knowledge.

The NRI uses a standard land capability classification, in which soils are classified based on their capability for sustained production of cultivated crops and pasture plants (Troeh and Thompson, 1993). Under this classification, the land of Class I, being the best land with no serious limitations for cultivation, does not have immediate conservation needs. As expected, we found a strong negative effect of the Class I land indicator variable on the probability of conservation tillage adoption. A similar effect is reported in Uri (1998).

The effect of climatic variables on conservation tillage adoption is also consistent with agronomic science. As the soils tend to stay cooler and wetter with the reduced tillage, it was expected the conservation tillage be adopted easier in warmer regions and in regions with relatively less variable precipitation. The strong positive effect of the average daily maximum temperature and the opposite one of the average daily minimum temperature are in agreement with the expectations. The statistically significant negative effect of precipitation variability on adoption is consistent with a higher need for adequate soil drainage under reduced till.

\section{Costs of Sequestering Carbon}

In addition to the adoption model just discussed, the empirical analysis relies on the Site-Specific Pollution Production (SIPP) modeling system (Mitchell et al., 1997), which estimates the environmental effects of different management practices. The estimation of 
these systems used information from the Erosion Productivity Impact Calculator (EPIC) (Sharpley and Williams, 1988), the NASS and NRI databases (USDA/SCS, 1990), the USDA's Census of Agriculture, Cropping Practices Survey, and Crops County data (Babcock et al., 1997). The SIPP model is used here to estimate the difference in carbon emissions from conventional and conservation tillage. For this analysis, conventional tillage is defined as a tillage system that maintains less than 30 percent residue cover. Conservation tillage is assumed to be no-till and is defined as a tillage system that maintains at least 70 percent residue cover (CTIC, 1993).

To assess the costs of the alternative subsidy schemes outlined in section 2 , we compute the total cost of achieving a given level of carbon sequestration in two alternative ways:

$$
\begin{aligned}
& T C(k)=\sum_{i=1}^{N} G\left(\alpha\left(\bar{\pi}_{i}^{0}-k_{i}\right)+\tilde{\beta} x_{i}\right) \cdot k_{i} \cdot N A_{i} \\
& \Delta T C(k)=\sum_{i=1}^{N}\left\{G\left(\alpha\left(\bar{\pi}_{i}^{0}-k_{i}\right)+\tilde{\beta} x_{i}\right)-G\left(\alpha \bar{\pi}_{i}^{0}+\tilde{\beta} x_{i}\right)\right\} \cdot k_{i} \cdot N A_{i},
\end{aligned}
$$

where $T C(k)$ represents the total cost of a particular set of subsidies when the subsidy payments are made to all adopters, regardless of whether they had previously adopted. In contrast, $\Delta T C(k)$ is the cost of a subsidy (or permits) program that would pay only new adopters. The expected total amount of carbon sequestered may also be computed in two ways, as $Q(k)$ or $\Delta Q(k)$ :

$$
\left.\begin{array}{l}
Q(k)=\sum_{i=1}^{N} G\left(\alpha\left(\bar{\pi}_{i}^{0}-k_{i}\right)+\tilde{\beta} x_{i}\right) \cdot\left(Y 0\left(x_{i}\right)-Y 1\left(x_{i}\right)\right) \cdot N A_{i}, \\
\Delta Q(k)=\sum_{i=1}^{N}\left\{G\left(\alpha\left(\bar{\pi}_{i}^{0}-k_{i}\right)+\tilde{\beta} x_{i}\right)-G\left(\alpha \bar{\pi}_{i}^{0}+\tilde{\beta} x_{i}\right)\right\} \cdot\left(Y 0\left(x_{i}\right)-Y 1\left(x_{i}\right)\right) \cdot N A_{i},
\end{array}\right\}
$$

where $Q(k)$ corresponds to the total amount of carbon sequestered and would be the appropriate measure of sequestered carbon if the baseline is set such that total carbon storage is counted. Alternately, $\Delta Q(k)$ is the expected total amounts of carbon 
sequestered due to the switch from conventional to conservation tillage and would be appropriate if the baseline allows only new carbon storage to be counted.

The quantities (11) and (12) have been estimated using all 13,477 1992 NRI points located in Iowa, where the crop grown in 1992 was corn, soybeans, wheat, sorghum, or hay. The adoption probabilities are predicted from the estimated model, and the value of $Y 0\left(x_{i}\right)-Y 1\left(x_{i}\right)$ has been predicted using the meta-model developed by Mitchell et al. (1997). The values $N A_{i}$ equal the NRI expansion factors. The latter, by definition, are the weights that ensure proper aggregation to the state cropland totals (Nusser and Goebel, 1997).

These expressions provide the basis for computing the average cost of sequestered carbon for the subsidy/credit programs identified earlier. In particular, we compute the average cost per ton of sequestered carbon under the following subsidy/market scenarios:

1. A single per acre subsidy, payments made to all adopters,

$$
\frac{T C(\bar{k})}{Q(\bar{k})} \text { and } \frac{T C(\bar{k})}{\Delta Q(\bar{k})},
$$

2. A single per acre subsidy, payments made only to new adopters,

$$
\frac{\Delta T C(\bar{k})}{Q(\bar{k})} \text { and } \frac{\Delta T C(\bar{k})}{\Delta Q(\bar{k})},
$$

3. A price discriminating subsidy, payment to all adopters,

$$
\frac{T C\left(k^{*}\right)}{Q\left(k^{*}\right)} \text { and } \frac{T C\left(k^{*}\right)}{\Delta Q\left(k^{*}\right)}, \text { and }
$$

4. A price discriminating subsidy, payment to new adopters,

$$
\frac{\Delta T C\left(k^{*}\right)}{Q\left(k^{*}\right)} \text { and } \frac{\Delta T C\left(k^{*}\right)}{\Delta Q\left(k^{*}\right)},
$$

where $\mathrm{k}^{*}$ represents the vector of minimum payment subsidies and $\bar{k}$ represents the single subsidy level. Note that the average costs are reported two ways for each subsidy level, one assuming an allowable baseline of only the additional carbon sequestered over previous levels (DQ(.)) in the denominator) and the other allowing all carbon $(\mathrm{Q}()$.$) .$ Clearly the average costs of carbon sequestered will be much lower if the costs can be 
averaged over the entire stock of carbon stored in the soil, rather than the increment attributable solely to the subsidy.

Figure 1 shows the average costs of the four subsidy programs under the assumption that credit for carbon sequestered is provided only for the increment in carbon levels (DQ). As expected the single subsidy paying all adopters is by far the most expensive. Likewise, the cost of the price discriminating subsidy is quite high when all adopters must be paid. However, both subsidy schemes have much lower per unit costs when only new adopters are paid, as represented by the lower two curves. In this case, about $1 \mathrm{mmt}$ of carbon can be acquired for $\$ 190$ from a discriminating subsidy and \$270 from a single subsidy. These values are close to SOC valuation by agronomists (Lal, 1998).

It is important to recognize that the social costs are the same whether only new adopters or all adopters are paid (and are represented by the lower curves) as the difference is merely a transfer. However, when considering the governmental costs of a subsidy program of the amount of money that might flow into agriculture as a result of a carbon market, the difference is of real interest.

Figure 2 reports the results for the same four sets of subsidy schemes, but under the scenario in which total carbon sequestered is included in the baseline. In this situation, average costs are dramatically lower (note the difference in the scale used both on the vertical and on the horizontal axis). Under any of the four subsidies, but particularly those that pay only new adopters, agriculture is predicted to be very competitive in being able to supply carbon reductions at low prices. Note, that the curves on Figure 2, are the average not marginal cost curves. Consequently, they are not the aggregate carbon supply schedules.

Finally, note that the difference between the single and discriminating subsidy decreases as the amount of carbon supply increases because the amount of flexibility in the minimum cost program declines. This loss of flexibility arises because as carbon supply increases there are fewer and fewer low-cost providers of carbon and fewer and fewer producers who are selling their fixed supply of carbon to the market. 


\section{Conclusions}

The purpose of this research was to examine various policy instruments that promote carbon sequestration in agricultural soils and mitigate greenhouse gas emissions through increased adoption of conservation tillage. The expected cost of carbon sequestration was estimated for four subsidy programs under two baseline scenarios.

Although the lowest payment cost can be achieved by a price discriminating subsidy, such a scheme may not be viable, either politically or due to prohibitively high administrative and enforcement costs. However, subsidies that permit some differentiation are very common in agriculture (such as the EQIP and Conservation Reserve Program [CRP]), thus investigating the least cost approach provides a useful lower bound on the costs of a subsidy scheme. In contrast, a single subsidy is less efficient, but will have lower administrative and political costs. Results of this study indicate that the payments associated with a price discriminating subsidy will be up to 4.1 times lower than a single price subsidy.

The average cost per ton of carbon sequestered through conservation tillage practices is largely affected by the choice of a baseline regardless of whether a single or price discriminating subsidy is used. Likewise, costs are much higher when payments must be made to all farmers employing conservation tillage, rather than just those adopting anew in response to the subsidy. Although neither result is surprising, it is important to understand the magnitude of these differences when considering the alternative policy design.

Several important limitations to this research should be mentioned at this juncture. First, as described in the empirical analysis, the estimates are based on meta-models using EPIC model simulations of carbon in agricultural soils. Improved estimates of the carbon sequestration potential are currently being developed using the more accurate CENTURY model. The cost estimates reported here may be sensitive to the carbon estimates from these physical models. Second, the results presented here apply to Iowa, where relatively high adoption rates are already present. They may not generalize well to other states or regions where different soil characteristics, weather, and other factors are present. 
Table 1. Summary statistics for variables in the logit estimation ${ }^{\text {a }}$

\begin{tabular}{|c|c|c|c|c|c|}
\hline Variable & Units & $\begin{array}{c}\text { Sample } \\
\text { Mean }\end{array}$ & $\begin{array}{c}\text { Sample } \\
\text { Standard } \\
\text { Deviation } \\
\end{array}$ & Minimum & Maximum \\
\hline $\begin{array}{l}\text { Conservation tillage } \\
(1-\text {-yes, } 0 \text {-no) }\end{array}$ & Number & 0.62 & 0.48 & 0 & 1 \\
\hline $\begin{array}{l}\text { Net returns to conventional } \\
\text { tillage, corn }{ }^{\mathrm{b}}\end{array}$ & $\$$ per acre & 145 & 23 & 67 & 185 \\
\hline $\begin{array}{l}\text { Net returns to conventional } \\
\text { tillage, soybeans }{ }^{c}\end{array}$ & $\$$ per acre & 109 & 14 & 68 & 141 \\
\hline $\begin{array}{l}\text { Net returns to conventional } \\
\text { tillage, other crops } \mathrm{d}_{\mathrm{d}, \mathrm{e}}\end{array}$ & $\$$ per acre & 92 & 43 & -40 & 158 \\
\hline $\begin{array}{l}\text { Other crop (1-other crop }{ }^{d}, \\
0 \text {-soybeans or corn) }\end{array}$ & Number & 0.08 & 0.27 & 0 & 1 \\
\hline $\begin{array}{l}\text { Soil surface texture (2-fine, } \\
\text { 1-medium, } 0 \text {-coarse) }\end{array}$ & Number & 0.6 & 1.2 & 0 & 2 \\
\hline Land slope & Percent & 4.1 & 3.9 & 0.1 & 26.0 \\
\hline Soil permeability & Inches per hour & 1.71 & 2.18 & 0.03 & 20.00 \\
\hline $\begin{array}{l}\text { Soil available water } \\
\text { capacity }\end{array}$ & Percent & 18.4 & 2.8 & 4.0 & 31.0 \\
\hline Class I land (1-yes, 0-no) & Number & 0.10 & 0.30 & 0 & 1 \\
\hline $\begin{array}{l}\text { Mean of the daily } \\
\text { maximum temperature } \\
\text { during the corn growing } \\
\text { season }\end{array}$ & Fahrenheit & 78.7 & 1.8 & 72.9 & 82.4 \\
\hline $\begin{array}{l}\text { Mean of the daily } \\
\text { minimum temperature } \\
\text { during the corn growing } \\
\text { season }\end{array}$ & Fahrenheit & 55.6 & 2.0 & 50.0 & 59.8 \\
\hline $\begin{array}{l}\text { Mean of the daily } \\
\text { precipitation during the } \\
\text { corn growing season }\end{array}$ & Inches & 0.141 & 0.012 & 0.114 & 0.173 \\
\hline $\begin{array}{l}\text { Standard deviation of the } \\
\text { daily precipitation during } \\
\text { the corn growing season }\end{array}$ & Inches & 0.331 & 0.027 & 0.276 & 0.417 \\
\hline
\end{tabular}


Table 2. Maximum -likelihood estimates for parameters of the logit model

\begin{tabular}{|c|c|c|c|}
\hline $\begin{array}{l}\text { Variable } \\
\end{array}$ & Parameter & Estimate & Standard Error of Estimator ${ }^{2}$ \\
\hline $\begin{array}{l}\text { Net returns to conventional } \\
\text { tillage, corn }\end{array}$ & $\beta_{1}$ & -0.0121 & $0.0029^{*}$ \\
\hline $\begin{array}{l}\text { Net returns to conventional } \\
\text { tillage, soybeans }\end{array}$ & $\beta_{2}$ & -0.0136 & $0.0039^{*}$ \\
\hline $\begin{array}{l}\text { Net returns to conventional } \\
\text { tillage, other crops }\end{array}$ & $\beta_{3}$ & -0.0018 & 0.0051 \\
\hline Other crop dummy & $\beta_{4}$ & -2.87 & $0.66^{*}$ \\
\hline Soil surface texture & $\beta_{5}$ & -0.114 & $0.062^{* * * *}$ \\
\hline Land slope & $\beta_{6}$ & 0.029 & $0.017^{* * *}$ \\
\hline Soil permeability & $\beta_{7}$ & 0.070 & $0.038^{* * *}$ \\
\hline Soil available water capacity & $\beta_{8}$ & 801 & $305^{*}$ \\
\hline Class I land & $\beta_{9}$ & -0.34 & $0.19^{* * * *}$ \\
\hline $\begin{array}{l}\text { Mean of the daily maximum } \\
\text { temperature during the corn } \\
\text { growing season }\end{array}$ & $\beta_{10}$ & 0.135 & $0.038^{*}$ \\
\hline $\begin{array}{l}\text { Mean of the daily minimum } \\
\text { temperature during the corn } \\
\text { growing season }\end{array}$ & $\beta_{11}$ & -0.147 & $0.048^{*}$ \\
\hline $\begin{array}{l}\text { Mean of the daily precipitation } \\
\text { during the corn growing season }\end{array}$ & $\beta_{12}$ & 27.0 & $9.9^{*}$ \\
\hline $\begin{array}{l}\text { Standard deviation of the daily } \\
\text { precipitation during the corn } \\
\text { growing season }\end{array}$ & $\beta_{13}$ & -16.8 & $4.4^{*}$ \\
\hline Fraction of correct predictions & & 0.67 & \\
\hline Log (Likelihood) & & -864.0 & \\
\hline
\end{tabular}

${ }^{a}$ The standard errors are computed from analytic second derivatives.

${ }^{*},{ }^{* *}$, and ${ }^{* * *}$ Indicate statistical significance at the 1 percent, 5 percent, and 10 percent level, respectively. 
Figure 1. Expected Per Ton Cost of Sequestering Carbon Under Different Subsidy Schemes. Credit for the Carbon Sequestered due to the Subsidy Only.

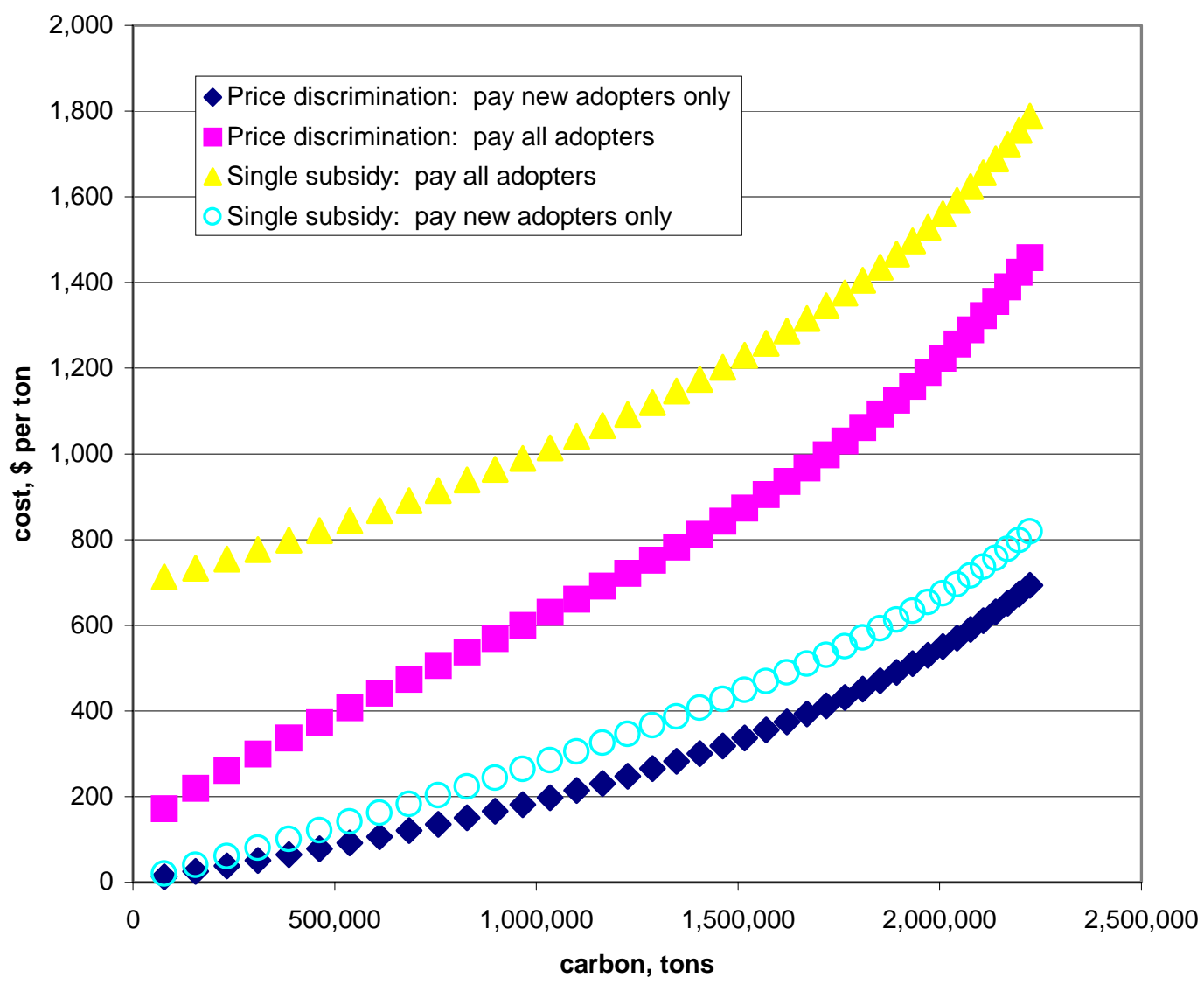


Figure 2. Expected Per Ton Cost of Sequestering Carbon Under Different Subsidy Schemes. Credit for All Carbon Sequestered.

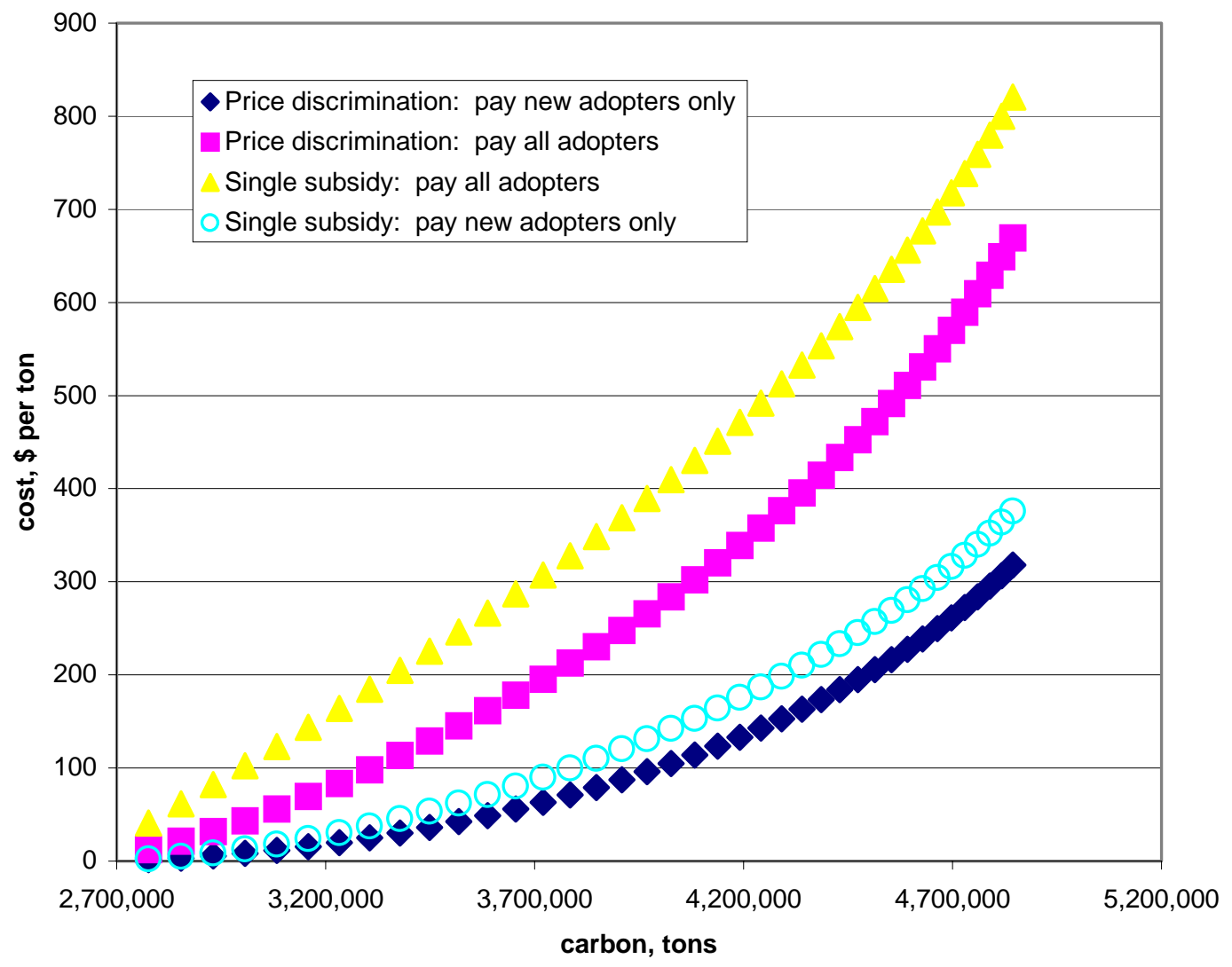




\section{Endnote}

1. The second order condition for a minimum is not met globally, since the adoption function $G\left(\alpha\left(\bar{\pi}^{0}-k\right)+\tilde{\beta} x\right)$ may be either concave or convex in $k$. A grid search was

conducted to find the value of $\lambda^{*}$ that minimized the total expected costs of sequestering an expected level of carbon. 


\section{References}

Allmaras, R. R., and R. H. Dowdy. 1985. "Conservation Tillage Systems and Their Adoption in the United States." Soil and Tillage Research 5: 197-222.

Amemiya, T. 1981. “Qualitative Response Models: A Survey," Journal of Economic Literature 19(1981):483.

Antle, J., S. Capalbo, S. Mooney, E. Elliott, and K. Paustian. 2000. "Economics of Agricultural Soil Carbon Sequestration in the Northern Plains," Research Discussion Paper No. 38, Trade Research Center, Montana State University.

Babcock, B., T. Campbell, P. Gassman, T. Hurley, P. Mitchell, T. Otake, M. Siemers, and J. Wu. 1997. Resource and Agricultural Policy Systems 1997: Agricultural and Environmental Outlook. Center for Agricultural and Rural Development, Iowa State University, Ames, IA.

Climate Change Sectretariat (UNFCCC). 1998. Kyoto Protocol to the United Nations Framework Convention on Climate Change. http://www.cop3.de/.

Conservation Tillage Information Center (CTIC). 1993. National Residue Management Survey. National Association of Conservation Districts, West Layfayette, IN.

Earthinfo. 1995. NCDC Summary of the Day. Earthinfo Inc., Boulder, CO.

Lal, R., J. M. Kimble, R. F. Follet, and C. V. Cole. 1998. The Potential of U.S. Cropland to Sequester Carbon and Mitigate the Greenhouse Effect. Ann Arbor, MI: Sleeping Bear Press.

Maddala, G. S. Limited-Dependent and Qualitative Variables in Econometrics. Cambridge University Press, 1983.

Mitchell, P. D., 1997. "Cost of Production Systems Budgets.” CARD Technical Report 97-TR 37. Ames: Center for Agricultural and Rural Development, Iowa State University, Ames, IA.

Mitchell, P. D, P. G. Lakshminarayan, T. Otake, and B. A. Babcock. 1997. "The Impact of Soil Conservation Policies on Carbon Sequestration in Agricultural Soils of the Central United States." In Management of Carbon Sequestration in Soil. ." Rattan Lal, John M. Kimble, Ronald F. Follett, Bobby A. Stewart, editors. Boca Raton, FL: CRC Press, pp. 125-142. 
Nusser, S. M., J. J. Goebel. 1997. "The National Resources Inventory: A Long-Term Multi-Resource Monitoring Programme." Environmental and Ecological Statistics 4: 181-204.

Sandor, R. L., and J. R. Skees. 1999. “Creating a Market for Carbon Emissions.” Choices, First Quarter: 13-17.

Sharpley, A. N., and J. R. Williams (eds.). 1990. EPIC-Erosion Productivity Impact Calculator: Model Documentation. U. S. Department of Agriculture Technical Bulletin No. 1768. Washington, D.C.: USDA.

Troeh, F. R., and L. M. Thompson. 1993. Soils and Soil Fertility. Fifth edition. New York: Oxford University Press.

Uri, N. D. 1999. Conservation Tillage in U.S. Agriculture: Environmental, Economic, and Policy Issues. Binghamton, NY: Food Products Press. "Conservation Tillage and the Use of Energy and Other Inputs in U.S. Agriculture.” Energy Economics 20: 389-410.

United Nations. Framework Convention on Climate Change. 1992. United Nations Environment Programme Information Unit for Conventions. http://www.unep.ch/.

United States Department of Agriculture, National Agricultural Statistics Service (USDA/NASS). 1999. Crop Values: Final Estimates 1992-97. USDA/NASS, Washington, DC. Agricultural Handbook No. 963. 1997. Usual Planting and Harvesting Dates for U.S. Field Crops. USDA/NASS, Washington, DC. Agricultural Handbook No. 628. 1994. USDA-NASS Crops County Data 1991-92. Data files. USDA/NASS, Washington, DC. http://usda.mannlib.cornell.edu/usda/usda.html

United States Department of Agriculture, Soil Conservation Service (USDA/SCS). 1994. The 1992 National Resources Inventory Database. USDA/SCS, Washington DC.

Wu, J., and B. A. Babcock. 1998. "The Choice of Tillage, Rotation, and Soil Testing Practices: Economic and Environmental Implications." American Journal of Agricultural Economics 80: 494-511. 